\title{
Study of the Traffic Management System at an Apex Tertiary Care Teaching Hospital and Recommendations for Improvement
}

\author{
${ }^{1}$ Mukunda Chandra Sahoo, ${ }^{2}$ Shakti Kumar Gupta, ${ }^{3}$ DK Sharma, ${ }^{4}$ Sanjay Kumar Arya, ${ }^{5}$ Amit Lathwal
}

\begin{abstract}
Introduction: Hospital parking services often represent the very first contact patients and visitors have with our hospital and to make a positive perception of our hospital, we need ample patient and visitor parking. Over last decade, there has been a quantum increase in workload by 6 to 7 times and a corresponding increase in the number of vehicles entering the tertiary care teaching hospital premises. Aim of traffic management at tertiary care hospital is to decongest, improve and smoothen traffic by advocating lane discipline, platooning, signal lights, parking, footpaths, reducing the number of private vehicles, efficient public transport, car pooling, etc.
\end{abstract}

Aims and objective: To study vehicular traffic management system at a Apex Tertiary Care Teaching Hospital.

Methodology: This was done by survey of the area and observation of traffic flow and its measurement. The data, thus, collected were analyzed and based on the analysis an action plan was drawn.

Conclusion: As regards parking arrangements at the tertiary care teaching hospital are concerned, there is a need to create integrated parking lots on surface as well as basement of the buildings for parking of approximately 7600 vehicles which will also take into account the future needs. These parking lots should also include multilevel intelligent parking system with a computerized system of lifts stacking each car in a berth, and thus reducing the need for parking and service personnel.

Keywords: Intelligent parking, Parking lots, Traffic management, Valet system, Vehicles.

How to cite this article: Sahoo MC, Gupta SK, Sharma DK, Arya SK, Lathwal A. Study of the Traffic Management System at an Apex Tertiary Care Teaching Hospital and Recommendations for Improvement. Int J Res Foundation Hosp Healthc Adm 2015;3(2):110-113.

Source of support: Nil

Conflict of interest: None

\footnotetext{
${ }^{1,5}$ Assistant Professor, ${ }^{2,3}$ Medical Superintendent, ${ }^{4}$ Professor ${ }^{1}$ Indira Gandhi Institute of Medical Sciences, Patna, Bihar, India ${ }^{2}$ All India Institute of Medical Sciences, Dr RP Centre of Ophthalmic Sciences, New Delhi, India

${ }^{3}$ All India Institute of Medical Sciences, New Delhi, India

${ }^{4,5}$ Department of Hospital Administration, All India Institute of Medical Sciences, New Delhi, India
}

Corresponding Author: Mukunda Chandra Sahoo, Assistant Professor, Indira Gandhi Institute of Medical Sciences, Patna Bihar, India, e-mail: mcsahoo1@gmail.com

\section{INTRODUCTION}

Traffic management is designed to improve the local environment and safety, by reducing accidents, injuries, congestion and pollution, achieved by slowing traffic speeds or redirecting traffic to more suitable transport routes through various means. ${ }^{1}$ Traffic management entails influencing the traffic supply and demand in terms of time and place, in order to achieve a functionally effective system. Hospital parking services often represent the very first contact patients and visitors have with the hospital. Like heart attacks, traffic congestions are a lifestyle problem. When arteries get clogged, we get heart attacks and when roads get clogged we get gridlocks. ${ }^{2}$

If we really think about it, traffic management boils down to efficient 'space' management. It is to manage the utilization of a finite commodity like space on the streets. All measures taken or discussed to decongest, improve, smoothen traffic by advocating lane discipline, platooning, signal lights, parking, footpaths, lesser private vehicles, efficient public transport, car pooling, etc. boils down to the management of the available road space. All these need fail proof, nondiscriminatory, permanent, long-term solutions which have to be followed by one and all.

\section{AN OVERVIEW OF EXISTING TRAFFIC SYSTEM AT THE TERTIARY CARE HOSPITAL}

Background: The Apex Tertiary Care Hospital was planned as an 866 bedded hospital which has over a period of time increased to approximately 2424 beds. Over the last decade, there has been a quantum increase in workload by 6 to 7 times. This astronomical increase in workload has been far more than what was envisaged. To cater to this increased workload in the tertiary care hospital campus has undergone hazardous growth due to lack of prospective planning. The expansion of various buildings and facilities has taken place in an adhoc manner due to lack of proper planning. This has manifested in scattered structures, services, chaotic traffic and lack of parking spaces besides under utilization of land resulting in paucity of space for future expansion. Over 40,000 to 50,000 patients and visitors come to the Institute every day. A study conducted by tertiary care teaching hospital in 2003 concluded that 26,500 vehicles are parked in the Institute everyday. ${ }^{3}$ 


\section{Existing Layout of the Tertiary Care Hospital}

There are two types of traffic system in the hospital: (a) External traffic and (b) internal traffic.

\section{External Traffic}

- It is necessary to identify different types of traffic that traverses and sometimes crisscrosses the hospital.

- It is also essential to segregate the traffic at the perimeter so that it can be regulated inside.

\section{Internal Traffic}

- This relates to movement of staff, patients, attendants and goods within the hospital building.

\section{AIMS AND OBJECTIVES}

- To study the existing external vehicular traffic management system at an Apex Tertiary Care Hospital.

- To estimate the number of vehicles entering the campus and residual number of vehicles in the parking lots on different days of the week.

- To identify the problems pertaining to traffic management system at that Apex Tertiary Care Hospital.

- To suggest measures for improvement of the traffic management system at same Apex Tertiary Care Hospital.

\section{METHODOLOGY}

Study area: At the Apex tertiary care hospital.

Type of study: Descriptive observational study.

Methodology: Parking spaces in the tertiary care hospital campus were studied with the help of drawings of the campus and discussions with the officials. Traffic flow and traffic measurement was done by observation of the vehicles entering the campus, the routes followed and the parking spaces (Flow Chart 1).

A 4 days observational study (both full working day and Sunday/Holiday) was conducted in the month of October to count the vehicles (both four wheelers and two wheelers) entering the campus from all four gates of tertiary care hospital campus (Table 1).

\section{OBSERVATIONS}

\section{Existing Conditions}

\section{Entrance gates}

At present, there are four entrance and exit gates in the Apex Tertiary Care Hospital.

Gate 1: Main Hospital Gate (Aurobindo Marg)

Gate 2: Ring Road Gate (South Extension)

Gate 3: Yusuf Sarai Side, Campus Gate

Gate 4: Masjid Moth Gate
Flow Chart 1: Methodology used for conducting the study

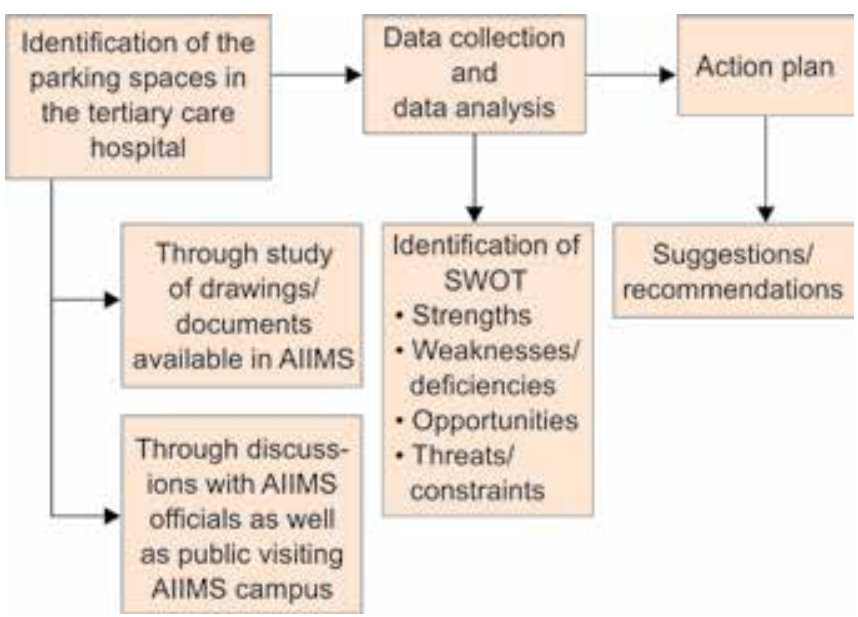

Table 1: Entry of vehicles into tertiary care hospital campus on full working day and Sunday

\begin{tabular}{llll}
\hline Sl. no. & Study conducted & Four wheelers & Two wheelers \\
\hline 1 & Full working day & 6006 & 5126 \\
2 & Sunday & 3408 & 2799 \\
3 & Full working day & 4716 & 2814 \\
4 & Sunday & 2895 & 2805 \\
\hline
\end{tabular}

\section{Existing Parking at Tertiary Care Teaching Hospital}

There are two types of parking space at the Apex Tertiary Care Hospital:

1. Parking Lot no: 'A' for faculty/staff:

- Faculty/staff car/scooter parking behind RPC which is operational from 7 am to $8 \mathrm{am}$.

- Faculty car/scooter parking in front of PC block, near examination section which is operational for 24 hours.

- Staff car/scooter parking near gate no. 2 in front of garage which is operational from $7 \mathrm{am}$ to $8 \mathrm{pm}$.

- Staff scooter parking near Administration block which is operational from 7 am to $8 \mathrm{pm}$.

2. Parking Lot no: ' $\mathrm{B}$ ' general public parking area

- Adjacent to mortuary operational for 24 hours.

- Masjid Moth land across Nallah operational from 7 am to 9 pm.

- Scooter parking on both sides of subway near exit gate operational for 24 hours.

To manage and control the scooter and car parking areas in the institute campus, there is a rate contract with an outside agency to ensure orderly parking of vehicles along with organizing the smooth flow of traffic.

The duties and responsibilities of the contractor are as follows:

- To manage the scooter/car parking areas for the general public, which have been earmarked for this purpose within the institute campus on charge of requisite fee from the public. 
- To manage the areas earmarked for parking of the vehicles of the Institute's staff/faculty free of cost.

- To manage the flow of traffic within the institutional areas of the main campus.

- To ensure that vehicles are not parked in 'No Parking' areas and to make arrangement for towing away the vehicles which have been parked in the unauthorized areas.

- To ensure that the flow of traffic is smoothly maintained without any hindrance and the roads meant for one way traffic are manned and ensuring that the vehicles are not allowed to violate traffic instructions issued from time to time.

- To provide adequate manpower to effectively run the services as mentioned earlier.

\section{Control of Traffic}

The traffic flow of vehicles is managed by the contractor by deploying traffic marshals/guides at the following locations for the durations as indicated against each:

- Ring Road Gate (South Extension) (6.00 am to $8.00 \mathrm{pm}$ )

- Main hospital entrance gate (Aurobindo Marg)

- Entrance gate near SBI

- Gate near director's bungalow

- In front of OPD

- The intersection between the boys hostels and administration block

- Entrance to IRCH/CN center

- In front of Dr RP Center

- Faculty car parking

- RPC Gents Hostel scooter parking

-do-

-do-

-do-

-do-

-do-

-do-

-do-

-do-

-do-

The contractor ensures that various instructions issued from time to time regarding movement of different kinds of vehicles, etc. are strictly enforced. The Deputy Chief Security Officer (Tertiary Care Hospital) of the institute issues detailed instructions regarding one way traffic, speed limit and timing, etc. The contractor is to ensure

- Proper maintenance of various traffic signboards installed in the institutional areas.

- Restrictions on the movement of such vehicles as are notified from time to time.

- Vehicles wrongly parked in various areas are towed away to a predesignated place within reasonable time at his own expenses without damage to the vehicles. Average number of vehicles (four wheelers) entering to tertiary care hospital campus on a full working day from four entrances $=6006+4716 / 2=10722 / 2=5361$.

Average number of vehicles (two wheelers) entering to tertiary care hospital on full working day campus from four entrances $=5126+2814 / 2=7940 / 2=3970$.
Average number of vehicles (four wheelers) entering to tertiary care hospital campus on a Sunday/Holiday from four entrances $=3408+2895 / 2=6303 / 2=3151$.

Average number of vehicles (two wheelers) entering to tertiary care hospital campus on a Sunday/Holiday from four entrances $=2799+2805 / 2=5604 / 2=2802$.

In addition to the above-mentioned parking areas (Table 2) vehicles are also parked in:

- Old nurses hostel, behind new private wards (cars) - 40

- Center for community medicine-10 cars + 20 two wheelers

- Gents hostel-100 cars + 100 two wheelers.

\section{Road Side Parking}

PMR department area-120 cars + 100 two wheelers

- Faculty parking (cars)—45

- VIP parking (cars)-20

- New private ward (cars)-20

- RPC hostel (two wheelers)-50

It was also observed that there are many vehicles parked in 'No parking areas' like in front of guest house, examination block, Amrit Kaur OPD, SBI Bank/Mother dairy, in-between IRCH and $\mathrm{CN}$ center, old private and new private wards. At any point of time approximate number of four wheelers and two wheelers parked in these areas were 1275 and 1350 respectively.

\section{Existing Methods of Traffic Control at the Tertiary Care Hospital}

- The contractor along with the security manages the traffic flow in one direction.

- Checks on unauthorized parking of vehicles.

- Cranes for towing away the vehicles parked in the unauthorized areas.

Table 2: Staff parking areas on Sunday

\begin{tabular}{|c|c|c|c|c|}
\hline Sl. no. & Parking area & Capacity & $\begin{array}{l}\text { No. of } \\
\text { vehicles } \\
\text { from } \\
\text { Monday to } \\
\text { Saturday }\end{array}$ & $\begin{array}{l}\text { No. of } \\
\text { vehicles }\end{array}$ \\
\hline 1 & $\begin{array}{l}\text { In front of examination } \\
\text { section (cars) }\end{array}$ & 130 & 130 & $10-15$ \\
\hline 2 & $\begin{array}{l}\text { In front of } \\
\text { examination section } \\
\text { (two wheelers) }\end{array}$ & 130 & 130 & $30-35$ \\
\hline 3 & $\begin{array}{l}\text { Near administrative } \\
\text { block (two wheelers) }\end{array}$ & 400 & 400 & $50-60$ \\
\hline 4 & Near ring road gate & 65 & 65 & $5-10$ \\
\hline 5 & $\begin{array}{l}\text { Parking behind RPC } \\
\text { (cars) }\end{array}$ & 25 & 25 & $10-15$ \\
\hline 6 & $\begin{array}{l}\text { Parking behind RPC } \\
\text { (two wheelers) }\end{array}$ & 50 & 50 & $10-50$ \\
\hline
\end{tabular}




\section{Problems Identified}

Following observations were made:

- Parking area is far from OPD and in-patient areas, a distance of about 600 meters.

- Parking lots are inadequate to accommodate the vehicles entering into the hospital.

- Parikrama Sewa (free battery operated vans) available for transporting patients and attendants within the campus is not sufficient during the morning hours to cater to the load of patients and attendants who need transportation from parking lots to the patient care areas as a large number of patients and attendants arrive within a short time span during morning hours.

- The roads are not pedestrian friendly. There are hardly any signs and directions for the convenience of patients.

- There is no parking area demarcated for the visitors of patients admitted in the paying wards.

\section{SWOT Analysis}

\begin{tabular}{ll}
\hline Strengths & Weakness \\
\hline - Land available & $\begin{array}{l}\text { Common entrance to OPD } \\
\text { and emergency }\end{array}$ \\
- Funds available & Distance from parking area \\
& to patient care area \\
- Roads and traffic system & - Inadequate parking space \\
already existing & Insufficient shuttle/ \\
& parikrama sewa vehicles \\
& The tertiary care hospital \\
& employees using vehicles \\
& for commuting from \\
& residential areas to the \\
& institute \\
Opportunities & Threats \\
Parking space at the tertiary & Chaotic traffic \\
care hospital metro rail & - Public dissatisfaction \\
\hline
\end{tabular}

\section{RECOMMENDATIONS}

The main objectives of the Traffic Management System is to provide a quality parking service facility to customers, facilitation of quick entry and exit from the parking points and reduction of travel time, streamline the entire traffic movement around the car parking area.

The following are the recommendations to augment the parking space which has been found to be inadequate in the present study:

Underground parking system: The most unique feature of such systems is that they can be planned under the new upcoming buildings.

Multilevel vertical parking system: These parking systems can be planned near the entrance gates of the tertiary care hospital.

Valet system: This service can be provided so that the need of the customer to park their own vehicle is eliminated.
In contrast to 'self-parking', where customers find parking on their own, in the valet system customers' vehicles are parked for them by another person.

Multilevel intelligent parking system: Driver intervention is not required as the system estimates the size of the lot and maneuvers the vehicle appropriately. A computerized system of lifts stacks each car in a berth, reducing the need for parking and service personnel. They require no ramps and can house twice the number of cars in half the space.

There is clearly a need for the planners to balance convenience with practicality within the given space constraints.

\section{CONCLUSION}

As regards parking arrangements at the tertiary care hospital are concerned, it was observed that all over the Institute, there is a parking space available for approximately 1200 cars and keeping in view the number of patients/visitors, this parking space is inadequate.

A large number of patients coming to the tertiary care hospital are from other states and due to their morbid conditions use vehicles to come to the tertiary care hospital. Most of the patients coming to emergency department come on vehicles out of which a large number are personal vehicles. Further a lot of expansion in terms of increasing the bed complement is planned in the future. This will help increase the pressure on the existing space. It is, hence, recommended that multiple parking areas in different parts of the institute be created keeping in mind their proximity with the patient care and office areas. Besides in all the upcoming buildings two to three basement levels should be earmarked for parking space. Based on the present, study there is an immediate parking space requirement of approximately 7600 vehicles which needs to be planned on the surface and basement. In light of above highlighted measures, it is hoped that this problem can be addressed in future. 4

\section{REFERENCES}

1. Available at: www.northamptonshire.gov.uk/NR/ rdonlyres/22956402-DFC7-418A-9D8F-06DEBADA97EB/0/ glossary.doc.

2. Cheria A, Edwin. Traffic management and decongestion. Available at: www.openspace.org.in/node/46 - 26k.

3. The Sunday Tribune-Spectrum Sunday, October 7, 2007.

4. 148th reports on Action taken by government on the recommendations/observations (Demand no. 46) of the department of health (Ministry of health and family welfare). 